\title{
Systematic lymphadenectomy in ovarian cancer at second-look surgery: a randomised clinical trial
}

\section{T Dell' Anna', M Signorelli', P Benedetti-Panici' ${ }^{2}$ A Maggioni ${ }^{3}$, R Fossati*,4, R Fruscio', R Milani', L Bocciolone ${ }^{3}$, A Buda', C Mangioni' ${ }^{\prime}$, G Scambia $^{5}$, R Angioli ${ }^{6}$, E Campagnutta $^{7}$, R Grassi $^{8}$ and F Landoni $^{3}$ \\ IS Gerardo Hospital, Monza, Italy; ${ }^{2}$ Department of Obtestrics and Gynecology, Università ' La Sapienza, Rome, Italy; ${ }^{3}$ stituto Europeo di Oncologia, Milan, Italy; ${ }^{4}$ Laboratory of Clinical Cancer Research, Mario Negri Institute, Via La Masa 19, Milan 20156, Italy; ${ }^{5}$ Department of Obtestrics and Gynecology, Università Cattolica del Sacro Cuore, Rome, Italy; ${ }^{6}$ Department of Obtestrics and Gynecology, Università Campus Biomedico, Rome, Italy; \\ ${ }^{7}$ Centro di Riferimento Oncologico, Aviano, Italy; ${ }^{8}$ Treviglio Hospital, Treviglio, Italy}

BACKGROUND: The role of systematic aortic and pelvic lymphadenectomy (SAPL) at second-look surgery in early stage or optimally debulked advanced ovarian cancer is unclear and never addressed by randomised studies.

METHODS: From January 199I through May 200 I, 308 patients with the International Federation of Gynaecology and Obstetrics stage IA-IV epithelial ovarian carcinoma were randomly assigned to undergo SAPL $(n=158)$ or resection of bulky nodes only $(n=150)$. Primary end point was overall survival (OS).

RESULTS: The median operating time, blood loss, percentage of patients requiring blood transfusions and hospital stay were higher in the SAPL than in the control arm $(P<0.00 I)$. The median number of resected nodes and the percentage of women with nodal metastases were higher in the SAPL arm as well (44\% vs $8 \%, P<0.00$ I and $24.2 \%$ vs 13.3\%, P:0.02). After a median follow-up of I I I months, 17I events (i.e., recurrences or deaths) were observed, and 124 patients had died. Sites of first recurrences were similar in both arms. The adjusted risk for progression and death were not statistically different (hazard ratio (HR) for progression $=1.18,95 \%$ confidence interval $(\mathrm{Cl})=0.87-1.59 ; P=0.29 ; 5$-year progression-free survival $(P F S)=40.9 \%$ and $53.8 \%$; HR for death $=1.04,95 \%$ $\mathrm{Cl}=0.733-1.49 ; \mathrm{P}=0.8 \mathrm{I} ; 5$-year $\mathrm{OS}=63.5 \%$ and $67.4 \%$, in the SAPL and in the control arm, respectively).

CONCLUSION: SAPL in second-look surgery for advanced ovarian cancer did not improve PFS and OS.

British Journal of Cancer (2012) I 07, 785-792. doi:I0.1038/bjc.2012.336 www.bjcancer.com

Published online 2 August 2012

(c) 2012 Cancer Research UK

Keywords: lymphadenectomy; second-look surgery; ovarian cancer

Epithelial ovarian cancer represents the nineth highest in cancer incidence and the fifth highest in site-specific causes of cancer deaths in women in the Western countries (Siegel et al, 2012). Only $25-30 \%$ of all cases are diagnosed with an early stage, good prognosis disease (Federation of Gynaecology and Obstetrics (FIGO) stage I-IIA; 5-year overall survival $(\mathrm{OS})=90-95 \%)$ as most patients are still diagnosed with an advanced stage, with a 5-year OS of 30-50\% (Holschneider and Berek, 2000; Trimbos et al, 2010).

The optimal treatment is currently based on cytoreductive surgery and adjuvant platinum-based chemotherapy. In early stage cancer the primary surgery includes hysterectomy, bilateral salpingo-oophorectomy, infracolic or infragastric omentectomy and peritoneal biopsies, whereas in case of advanced disease the goal is the complete cytoreduction of all visible tumour (Bristow et al, 2002; Timmers et al, 2010; Trimbos et al, 2010).

The role of lymphadenectomy as a part of the surgical treatment of ovarian cancer has been debated over the last 30 years Retroperitoneal lymph node involvement occurs in $\sim 5-25 \%$ and $50-80 \%$ of women with early and advanced ovarian cancer, respectively. Retrospective studies have suggested that removal of the lymph nodes is associated with an improvement of staging and a survival benefit (Chen and Lee, 1983; Di Re et al, 1989;

*Correspondence: Dr R Fossati; E-mail: roldano.fossati@marionegri.it Received 13 April 2012; revised 01 July 2012; accepted 06 July 2012; published online 2 August 2012
Burghadt et al, 1991; Benedetti-Panici et al, 1993; Kigawa et al, 1994; Kikkawa et al, 1995; Scarabelli et al, 1995; Spirtos et al, 1995; Di Re et al, 1996).

In Italy, in 1990, comprehensive programs, coordinated at the Mario Negri Institute (Milan), were designed to evaluate, by randomised clinical trials (RCT), the impact of lymphadenectomy in ovarian carcinoma. Such programme aimed at evaluating staging accuracy and survival in macroscopic disease confined to the pelvis Maggioni et al (2006) or in optimally debulked (previously defined as $<1 \mathrm{~cm}$ ) advanced stage (Benedetti-Panici et al, 2005).

This trial,was launched to assess the influence of lymphadenectomy, performed at second look after primary surgery and adjuvant chemotherapy, on the survival rates of women with stage IA-IV ovarian cancer.

\section{PATIENTS AND METHODS}

\section{Patient eligibility}

Patients with histologically proven epithelial ovarian carcinoma with FIGO stages IA-IV (FIGO Committee on Gynaecologic Oncology, 2009), after primary surgery, with or without adjuvant chemotherapy and no evidence of disease on chest, abdominal and pelvic computed tomography scan, were eligible for participation in the study.

Additional eligibility criteria included age of $>75$ years, the Karnofsky performance status of $\geqslant 80$. Patients who underwent 
retroperitoneal evaluation at first surgery or had second-look surgery $>12$ months after first surgery were not eligible. The study protocol was revised and accepted by Local Ethics Committees, and appropriate written informed consent was obtained from all patients.

\section{Randomisation procedures}

Random assignment of patients, who had an equal probability of assignment to either treatment arm, was carried out by a block arrangement that balances the treatment assignment within each site. Randomisation was performed centrally by telephone at the Mario Negri Institute, Milan.

Patients were randomly assigned intra-operatively after open laparotomy when the surgeon was sure that the tumour was properly debulked (residual tumour $<1 \mathrm{~cm}$ ).

Data from all eligible patients were analysed for survival on an intention-to-treat basis.

\section{Patient characteristics}

Pretreatment clinical and tumour characteristics, operative details of primary surgery, front-line chemotherapy and operative details of second look surgical procedures were collected soon after surgery.

Chemotherapy and initial follow-up data were collected 6 months after surgery, and further follow-up data were collected annually thereafter. Data were sent to the Mario Negri Institute, Milan.

\section{Surgical procedures}

Control arm An attempt to achieve an optimal cytoreduction for any metastatic peritoneal implants was carried on, followed by the resection of all suspicious lymph nodes of $\geqslant 1 \mathrm{~cm}$ in diameter.

Systematic lymphadenectomy arm Secondary cytoreductive surgery as detailed for the control arm was followed by systematic pelvic and aortic lymphadenectomy.

Pelvic lymphadenectomy included external and internal iliac, superficial and deep common iliac, superficial and deep obturator and presacral nodes Unilateral lymphadenectomy was allowed in unilateral tumours. Bilateral pelvic lymph node dissection was deemed satisfactory when at least 25 nodes were removed (12 in case of unilateral lymphadenectomy).

Aortic lymphadenectomy dissection began at the aortic bifurcation up to the renal vessels by removing superficial and deep intercavoaortic, precaval, paracaval and retrocaval, preaortic and paraaortic nodes aortic lymphadenectomy was considered appropriate when at least 15 nodes were removed. In case of previous diagnosis of unilateral right ovarian cancer stage IA-IIA the dissection of the paraaortic nodes was optional. Similarly, in case of previous diagnosis of unilateral left ovarian cancer stage IA-IIA the dissection of the paracaval nodes was optional In these cases, the aortic lymphadenectomy was considered appropriate when at least 10 nodes were removed.

\section{Second-line chemotherapy}

All patients, regardless of the trial arm, were recommended to undergo a second-line chemotherapy in case of microscopic positive histological findings (i.e., biopsies or cytology), in case of macroscopic tumour surgically converted to a complete cytoreduction or in case of any residual tumour at the second-look surgery. A 'consolidation' chemotherapy was optional in case of negative histology.

Patients found to have progressive disease on follow-up were provided with further treatment at the discretion of the treating physician.

\section{Statistical analysis}

The primary endpoint of this study was OS, defined as the time from randomisation to death from any cause.

Secondary endpoints included surgical morbidity and progression-free survival (PFS), defined as the time from randomisation to the earliest occurrence of progression or death from any cause.

In pre-trial analysis, we calculated that when a type I error is limited to.05 (two-tailed test), a total of about 300 patients would need to be accrued to afford an $80 \%$ power to detect a $36 \%$ relative reduction in the mortality hazard rate of patients in the systematic lymphadenectomy (i.e., increasing the 5-year survival rate from 64 to $75 \%$, which corresponds to a hazard ratio (HR) of 0.64).

Survival curves were estimated by the Kaplan-Meier method (Kaplan and Meier, 1958) and compared using the log-rank test (Peto et al, 1977).

Additional analyses were performed with the Cox proportional hazards model adjusting for multiple baseline characteristics. Proportional hazards assumptions were checked by plotting $\log \{-$ $\log [S(t)]\}$ against $\log t$ for each group and found to be satisfied (Parmar and Machin, 1995).

Comparison of proportions between groups was performed using a two-sided $\chi^{2}$ test or, if the number of patients in a given category was less than five, a two-sided Fisher's exact test. Continuous data, including number of resected nodes, operating time, blood loss and hospital stay, were expressed as medians with interquartile ranges and were compared using a two-sided Kruskal-Wallis (nonparametric) test.

\section{RESULTS}

\section{Patient accrual}

Between January 1991 and May 2001, 322 patients were enroled in the study at six centres. After pathological and clinical review, 14 patients were deemed ineligible. Figure 1 shows the trial flow diagram and details reasons for patient ineligibility.

\section{Patient characteristics}

The clinical and tumour characteristics of eligible patients are listed in Table 1. Characteristics appear to be well balanced across treatment arms.

Approximately $50 \%$ of patients had residual disease $>1 \mathrm{~cm}$ after primary surgery and the vast majority of patients received chemotherapy after primary cytoreductive surgery, 140 in the biopsy arm and 147 in the lymphadenectomy arm $(93 \%$ in each arm). In total, 21 women did not undergo chemotherapy, of which 16 out of 70 women with early stage IA-IIA ( 8 in each arms) and 5 out of 238 women with advanced stage IIB-IV ( 2 vs 3 in the two arms).

No differences in chemotherapy schedules were found between the two trial arms $(P=0.42) ; 98 \%$ of patients underwent platinumbased chemotherapy regimens, and only $2 \%$ of patients received non-platinum-based chemotherapy regimens. In particular, a platinum mono-chemotherapy was used in 108 women (47 assigned to lymphadenectomy vs 61 assigned to no-lymphadenectomy) a platinum-taxanes in 31 (14 vs 17) and platinum + others in 142 (76 vs 66) patients, respectively.

The median number of cycles administered was 6 (range 2-10).

At the end of second-look surgery 18 patients $(6 \%)$ had residual disease, all $<1 \mathrm{~cm}$.

\section{Surgical procedures}

The surgical procedures performed during second-look surgery before the randomisation are listed in Table 2 . 

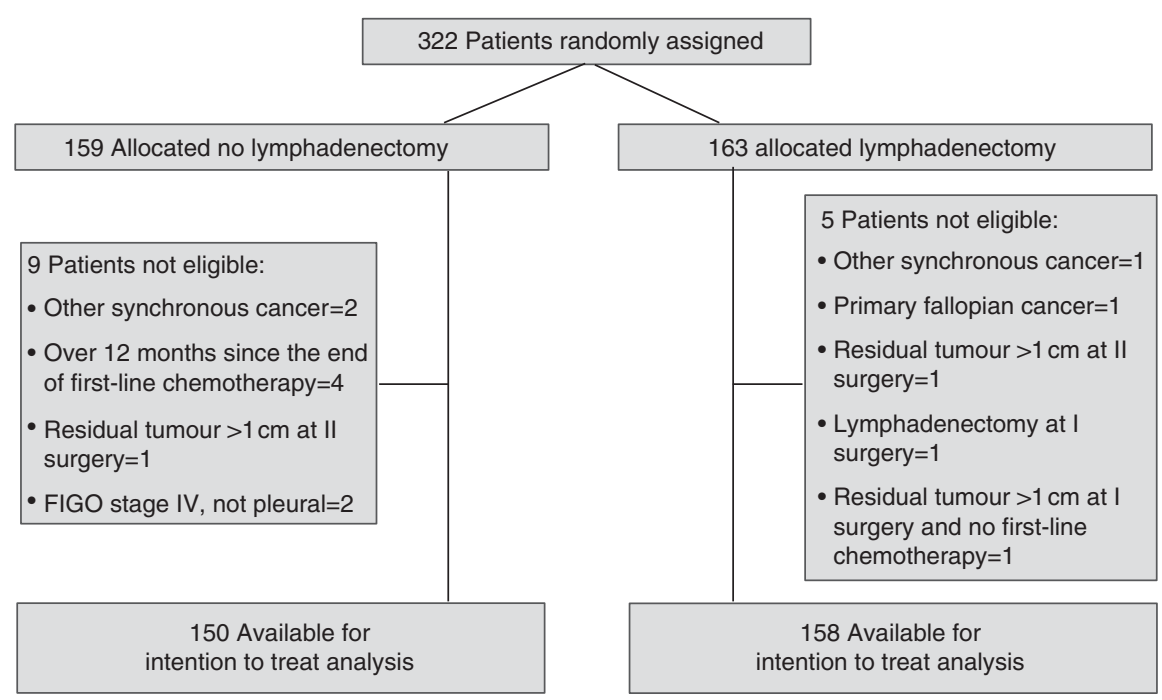

Figure I Consolidated Standards of Reporting Trial flow diagram for patients with stage IA-IV ovarian cancer who were accrued into the trial.

Table 3 shows the median number and inter-quartile range of resected nodes by treatment arm. In the systematic lymphadenectomy arm, the median number of removed pelvic and aortic lymph nodes was 23 (interquartile range $=15-33$ ) and 20 (interquartile range $=13-28$ ), respectively. Overall, the median number of removed nodes was 44 (interquartile range $=30-63$ ) in the lymphadenectomy arm and 8 (interquartile range $=4-14.5$ ) in the control arm. At least one positive pelvic or aortic node was detected in 58 women $(18.8 \%), 38$ in the lymphadenectomy arm and 20 in the non-lymphadenectomy arm $(24.2 \%$ vs $13.3 \%$, $P=0.02$ ).

In particular, in the group of women with stage IA-IIA disease, nodal metastases were found in 3/30 women in the lymphadenectomy arm $v s 2 / 40$ women in the non-lymphadenectomy arm. In the subgroup of women with stage IIB-IV disease, 35/128 women in the lymphadenectomy arm vs $18 / 110$ women in the nonlymphadenectomy arm had nodal metastases.

In the patients assigned to lymphadenectomy arm, nodal metastases were found in $8 / 59(13.6 \%)$ women with no evidence of residual tumour $v s$ in $30 / 99$ (30.3\%) women who had any residual tumour at the end of primary surgery $(P=0.165)$.

Furthermore, nodal metastases were depicted in the lymphadenectomy arm, in 26/123 (21.1\%) and 12/34 (35.3\%), in women with no evidence of peritoneal tumour $v s$ the presence of any tumour at the beginning of the second-look surgery $(P=0.088)$.

Systematic lymphadenectomy had a statistically significant impact on surgical parameters such as median operative time, blood loss, blood transfusions and the number of hospital days (Table 4).

Although the number of intra-operative complications was similar between the two arms (i.e., two in the control arm and seven in lymphadenectomy arm, $P=0.106$ ), systematic lymphadenectomy had greater perioperative and late morbidity (14 patients $v s 3$ patients in the control arm, $P=0.008$ ). Most of the difference in morbidity between the two trial arms was due to the formation of lymphocysts and lymphedema that occurred in six patients in the systematic lymphadenectomy group $v s$ no patients in the control arm. The frequency of remaining postoperative complications were as follows: radicular damage ( 2 vs 0 patients), intestinal fistula ( 1 vs 0 patients), hemoperitoneum (1 vs 0 patients), fever ( 2 vs 1 patients), surgical wound diastasis (0 vs 2 patients) and adhesive small bowel obstruction ( 2 vs 0 patient). No surgery-related deaths occurred.

\section{Second-line chemotherapy after second-look surgery}

Overall, 138 (45\%) out 308 patients received chemotherapy after second-look surgery ( $43 \%$ in the control arm and $47 \%$ in the systematic lymphadenectomy arm; $P=0.46$ ). In total, $79 \%$ of patients with macroscopic evidence of tumour at the beginning of second-look surgery or positive nodes underwent chemotherapy treatment whereas $28 \%$ of patients without evidence of the disease at second look and negative nodes underwent consolidation chemotherapy. No differences in chemotherapy schedules were found between the two trial arms with $70 \%$ of patients undergoing platinum or platinum-based chemotherapy regimens.

\section{Progression-free and OS}

At a median follow-up of 111 months (25-75th percentiles: 88-148 months) tumour has recurred in 163 patients $(52.9 \%)$ and 124 patients $(40.3 \%)$ have so far died. Recurrence was experienced by 74 patients $(49.3 \%)$ in the control arm and by 89 patients $(56.3 \%)$ who underwent systematic lymphadenectomy. The pattern of disease recurrences, stratified by stage of disease, are listed in Table 5.

Figures 2 and 3 depict the overall and PFS, respectively, for all eligible patients.

Median PFS was 68.7 months. At $3-5-10$ years, $58.8 \%$ vs $50.5 \%$, $53.8 \%$ vs $40.9 \%$ and $44.4 \%$ vs $39.4 \%$ of women in the control arm and in the lymphadenectomy arm, respectively, did not relapse. The HR for relapse in the group assigned to lymphadenectomy as compared with the group assigned to control was $1.18(95 \%$ confidence interval $(\mathrm{CI})=0.87-1.59 ; P=0.29)$.

Median OS was not reached at the time of analysis. At 3-5-10 years, $77.7 \%$ vs $79.6 \%, 67.4 \%$ vs $63.5 \%$ and $56.2 \%$ vs $54.2 \%$ of women in the control arm and in the lymphadenectomy arm, respectively, were alive. The HR for death in the group assigned to lymphadenectomy as compared with the group assigned to control was $1.04(95 \% \mathrm{CI}=0.733-1.49 ; P=0.81)$.

A Cox proportional hazards analysis was performed to adjust the treatment comparison for baseline characteristics. When stage was taken into account the new HRs for death and progression remained virtually unchanged (Table 6).

A subgroup analysis in women with stage IA-IIA and stage IIB-IV disease was performed to evaluate the impact of lymphadenectomy in the different subsets of women. In the early stage subgroup the HR for relapse was $1.3(95 \% \mathrm{CI}=0.46-3.77 ; P=0.60)$ 
Table I Patients characteristics

\begin{tabular}{|c|c|c|c|c|}
\hline \multirow[b]{2}{*}{ Characteristics } & \multicolumn{2}{|c|}{$\begin{array}{c}\text { No } \\
\text { lymphadenectomy } \\
(N=150)\end{array}$} & \multicolumn{2}{|c|}{$\begin{array}{l}\text { Lymphadenectomy } \\
\qquad(N=158)\end{array}$} \\
\hline & $n$ & $\%$ & $n$ & $\%$ \\
\hline Median age (25-75th percentiles) & \multicolumn{2}{|c|}{$52(45-60)$} & \multicolumn{2}{|c|}{$50(44-58)$} \\
\hline \multicolumn{5}{|l|}{ FIGO stage (primary surgery) } \\
\hline I - n & 36 & 24.0 & 26 & 16.5 \\
\hline IA & 8 & & 6 & \\
\hline $\mathrm{IB}$ & 5 & & I & \\
\hline IC & 23 & & 19 & \\
\hline$\|$ & 17 & 11.5 & 25 & 15.8 \\
\hline$\| \mathrm{A}$ & 4 & & 4 & \\
\hline$\| B$ & 7 & & 14 & \\
\hline$\| C$ & 6 & & 7 & \\
\hline III & 90 & 60.0 & 99 & 62.6 \\
\hline IIIA & 3 & & 7 & \\
\hline$\| \mathrm{II}$ & 11 & & 7 & \\
\hline$\| I C$ & 76 & & 85 & \\
\hline IV & 6 & 4.0 & 8 & 5.1 \\
\hline Missing data & । & 1.5 & 0 & 0 \\
\hline \multicolumn{5}{|l|}{ Residual tumour at first surgery } \\
\hline Absent & 57 & 38.0 & 59 & 37.3 \\
\hline$\leqslant 1 \mathrm{~cm}$ & 8 & 5.3 & 21 & 13.3 \\
\hline$>1 \mathrm{~cm}$ & 73 & 48.7 & 72 & 45.6 \\
\hline Missing data & 12 & 8.0 & 6 & 3.8 \\
\hline \multicolumn{5}{|l|}{ Tumour grade } \\
\hline One well differentiated & 17 & 11.3 & 12 & 7.6 \\
\hline $\begin{array}{l}\text { Two moderately well } \\
\text { differentiated }\end{array}$ & 36 & 24.0 & 35 & 22.2 \\
\hline Three poorly differentiated & 87 & 58.0 & 105 & 66.5 \\
\hline Missing data & 10 & 6.7 & 6 & 3.8 \\
\hline \multicolumn{5}{|l|}{ Cell type } \\
\hline Serous & 79 & 52.7 & 100 & 63.3 \\
\hline Endometriod & 31 & 20.7 & 15 & 9.5 \\
\hline Mucinous & 8 & 5.3 & 7 & 4.4 \\
\hline Clear-cell & 8 & 5.3 & 13 & 8.2 \\
\hline Undifferentiated & 8 & 5.3 & 15 & 9.5 \\
\hline Other & 8 & 5.3 & 6 & 3.8 \\
\hline Missing data & 8 & 5.3 & 2 & 1.3 \\
\hline \multicolumn{5}{|l|}{ Residual tumour at II look surgery } \\
\hline Absent & 118 & 78.7 & 123 & 77.8 \\
\hline Surgically converted to absent & 22 & 14.7 & 26 & 16.4 \\
\hline$\leqslant 1 \mathrm{~cm}$ & 10 & 6.7 & 8 & 5.1 \\
\hline Missing data & 0 & 0 & । & 0.6 \\
\hline
\end{tabular}

Abbreviation: FIGO = Federation of Gynaecology and Obstetrics.

and HR for death was $1.26(95 \% \mathrm{CI}=0.41-3.91 ; P=0.69)$. In advanced stage the HR for relapse was $1.06(95 \% \mathrm{CI}=0.77-1.45$; $P=0.73)$ and for death was $0.96(95 \% \mathrm{CI}=0.66-1.40 ; P=0.83)$.

We performed also a separate survival analyses also in women with no residual tumour $v s$ women with any residual disease at the end of primary surgery. Among women completely debulked the $\mathrm{HR}$ for relapse was $1.60(95 \% \mathrm{CI}=0.86-2.97 ; P=0.14)$ and for death was $1.75(95 \% \mathrm{CI}=0.86-3.57 ; P=0.12)$, whereas in women not completely debulked the $\mathrm{HR}$ for relapse was 1.60 $(95 \% \mathrm{CI}=0.86-2.97 ; P=0.14)$ and for death was $0.81(95 \% \mathrm{CI}=$ $0.53-1.23 ; P=0.32)$.

\section{DISCUSSION}

Second-look surgery for ovarian cancer was introduced in the clinical practice with the main objective of accurately assessing the pathological findings in the peritoneal cavity and in pelvic and
Table 2 surgical procedures at the II look surgery

\begin{tabular}{|c|c|c|c|}
\hline $\begin{array}{l}\text { Surgical } \\
\text { procedures }\end{array}$ & $\begin{array}{c}\text { No } \\
\text { lymphadenectomy } \\
(N=150)\end{array}$ & $\begin{array}{l}\text { Lymphadenectomy } \\
\qquad(N=158)\end{array}$ & $\begin{array}{c}\text { Total } \\
(N=308) \\
(\%)\end{array}$ \\
\hline Hysterectomy & 55 (36.9\%) & $59(37.8 \%)$ & $114(37.4)$ \\
\hline Missing data & 1 & 2 & $3(0.9)$ \\
\hline Unilateral or bilateral & $42(28 \%)$ & $38(24 \%)$ & $80(26)$ \\
\hline $\begin{array}{l}\text { salpingo-oophorectomy } \\
\text { Missing data }\end{array}$ & 14 and 28 & 13 and 25 & $\begin{array}{c}27 \text { and } 53 \\
2(0.6)\end{array}$ \\
\hline Omentectomy & $107(71.3 \%)$ & 101 (64\%) & $208(67.5)$ \\
\hline Missing data & I & $i$ & $2(0.6)$ \\
\hline Appendectomy & $36(24.2 \%)$ & $45(28.7 \%)$ & $81(26.5)$ \\
\hline Missing data & I & 1 & $2(0.6)$ \\
\hline Small bowel resection & | (0.7\%) & 0 & I (0.3) \\
\hline Missing data & 1 & 1 & $2(0.6)$ \\
\hline $\begin{array}{l}\text { Rectosigmoid or colon } \\
\text { resection }\end{array}$ & $6(4 \%)$ & I (0.6\%) & $7(2.3)$ \\
\hline Missing data & I & I & $2(0.6)$ \\
\hline Pelvic peritonectomy & $8(5.4 \%)$ & $8(5.1 \%)$ & $16(5.2)$ \\
\hline Missing data & 1 & 1 & $2(0.6)$ \\
\hline $\begin{array}{l}\text { Diaphragm stripping/ } \\
\text { resection }\end{array}$ & $4(2.7 \%)$ & I (0.6\%) & $5(1.6)$ \\
\hline Missing data & I & I & $2(0.6)$ \\
\hline
\end{tabular}

Table 3 Median number (25-75th percentiles) of resected nodes by treatment arm

\begin{tabular}{lccc}
\hline Nodal site & $\begin{array}{c}\text { No } \\
\text { lymphadenectomy } \\
(\mathbf{N}=\mathbf{I 5 0})\end{array}$ & $\begin{array}{c}\text { Lymphadenectomy } \\
(\mathbf{N}=\mathbf{I 5 8})\end{array}$ & $\mathbf{P}$ \\
\hline Pelvic & $5(1.5-10)$ & $23(15-33)$ & $<0.001$ \\
Lumbo-aortic & $2(0-4)$ & $20(13-28)$ & $<0.001$ \\
Pelvic and lumbo-aortic & $8(4-14.5)$ & $44(30-63)$ & $<0.001$ \\
Missing data & 6 & 1 & \\
\hline
\end{tabular}

Table 4 Operative details and postoperative hospital stay

\begin{tabular}{|c|c|c|c|}
\hline $\begin{array}{l}\text { Operative } \\
\text { details }\end{array}$ & $\begin{array}{c}\text { No } \\
\text { lymphadenectomy } \\
(N=150)\end{array}$ & $\begin{array}{l}\text { Lymphadenectomy } \\
\qquad(N=158)\end{array}$ & $P$ \\
\hline $\begin{array}{l}\text { Median operating } \\
\text { time (min) }\end{array}$ & 135 & 230 & $<0.001$ \\
\hline $\begin{array}{l}\text { (25-75th } \\
\text { percentiles) }\end{array}$ & $(100-180)$ & $(180-270)$ & \\
\hline Missing data & 7 & 13 & \\
\hline $\begin{array}{l}\text { Median blood loss }(\mathrm{ml}) \\
\quad(25-75 \text { th } \\
\text { percentiles })\end{array}$ & $\begin{array}{c}200 \\
(150-350)\end{array}$ & $\begin{array}{c}400 \\
(300-700)\end{array}$ & $<0.001$ \\
\hline Missing data & 17 & 21 & \\
\hline Patients transfused (\%) & $14(9.3 \%)$ & $46(29.1 \%)$ & $<0.001$ \\
\hline $\begin{array}{l}\text { Median hospital } \\
\text { stay (days) }\end{array}$ & 6 & 7 & 0.0015 \\
\hline $\begin{array}{l}\text { (25-75th } \\
\text { percentiles) }\end{array}$ & (5-8) & $(6-8)$ & \\
\hline Missing data & 11 & 20 & \\
\hline
\end{tabular}

aortic nodes areas in women with apparent complete response to the front-line chemotherapy. The philosophy of second-look surgery is based on the belief that an early identification of microor macroscopic-resistant disease to the first-line chemotherapy, the debulking of such resistant tumour and the immediate consolidation or the second-line chemotherapy could increase the OS. A secondary objective of the second-look surgery was the restaging of women who underwent primary inadequate surgery 
Table 5 Site of disease recurrence by stage and treatment arm

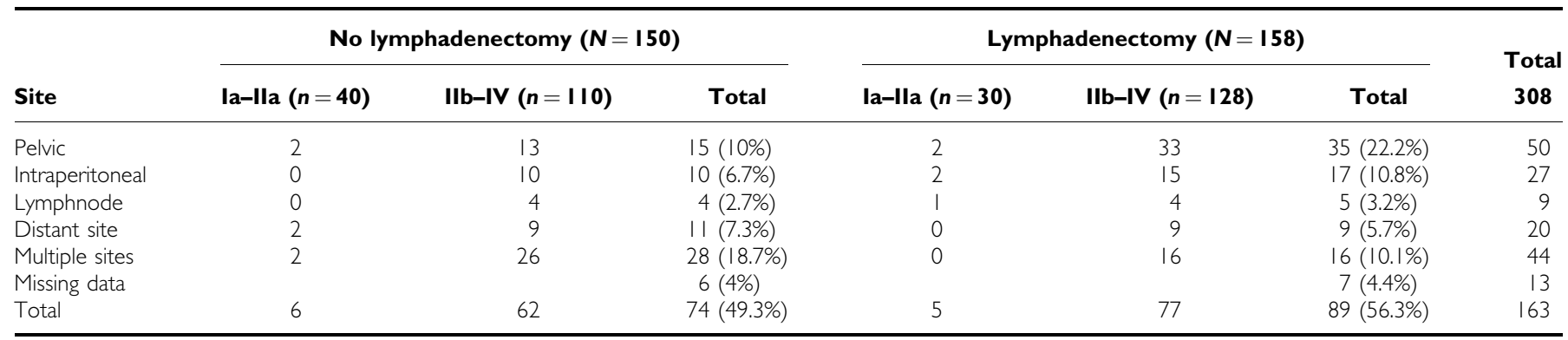

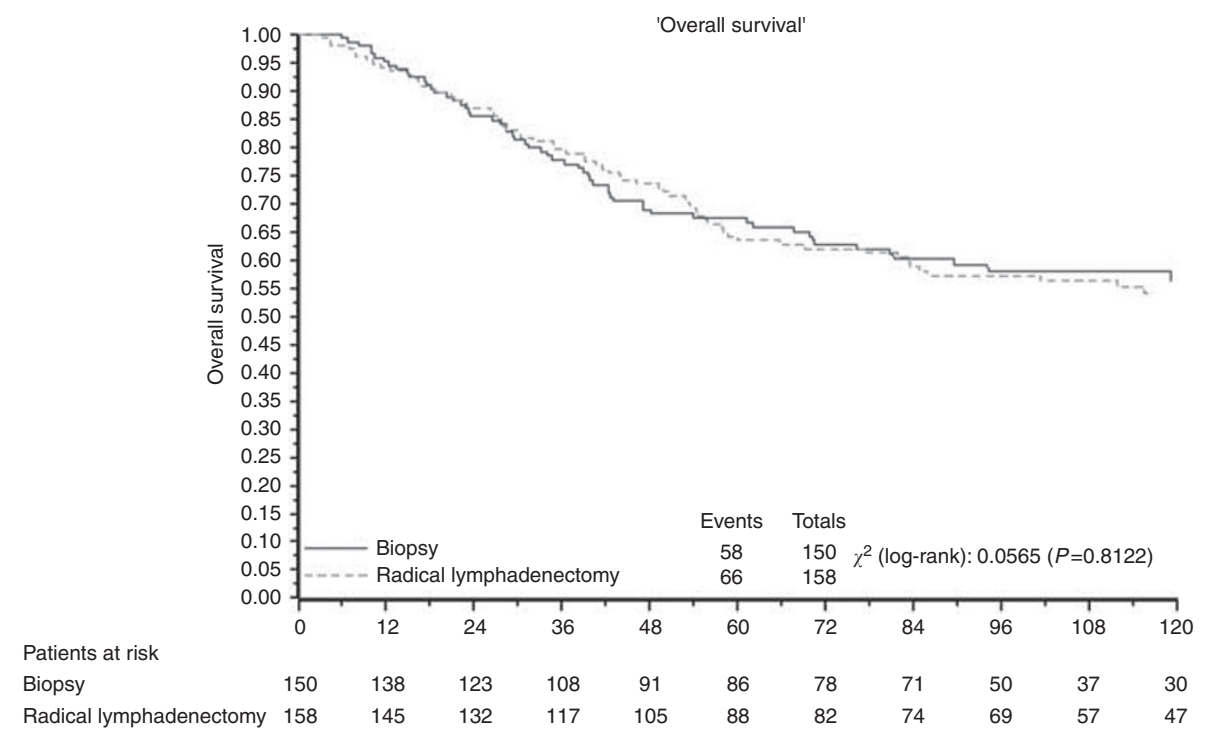

Figure 2 OS for all eligible patients.

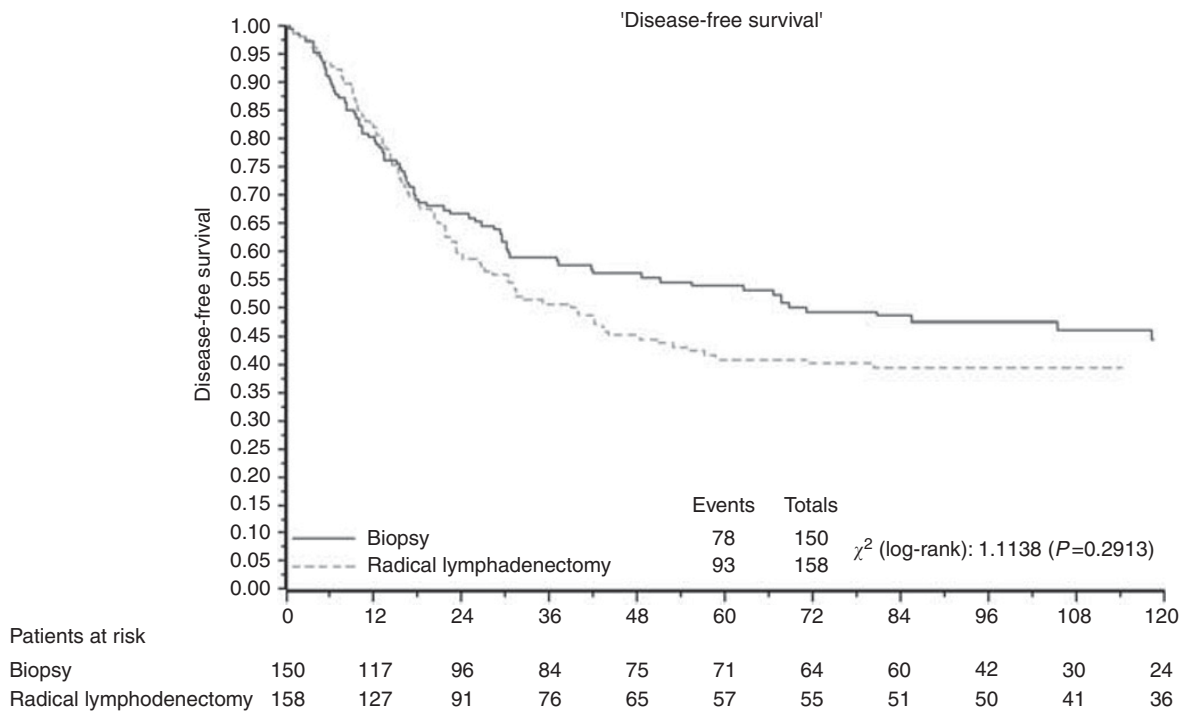

Figure 3 PFS for all eligible patients.

and to complete the endo- or retro-peritoneal cytoreduction if macroscopic disease is encountered (Podratz and Cliby, 1994).

The most important clinical variable influencing the presence of tumour at second-look surgery is stage. Residual tumour at second look has been described in $5-15 \%$ of women with early stage cancer, according to the adequateness of surgical staging at primary surgery. Conversely, in advanced stage, a positive histology at second look has been described in almost $25 \%$ in 
Table 6 Multivariable Cox proportional hazards analysis for PFS and OS to adjust the risk associated with therapy for various prognostic factors ${ }^{2}$

\begin{tabular}{|c|c|c|c|c|}
\hline \multirow[b]{2}{*}{ Prognostic factor } & \multicolumn{2}{|l|}{ PFS } & \multicolumn{2}{|l|}{ os } \\
\hline & HR $(95 \%$ Cl) & $P$ & HR $(95 \% \mathrm{Cl})$ & $\boldsymbol{P}$ \\
\hline \multicolumn{5}{|c|}{ Treatment arm } \\
\hline $\begin{array}{l}\text { No lymphadenectomy } \\
\text { Lymphadenectomy }\end{array}$ & $\begin{array}{c}1 \\
1.11(0.82-1.50)\end{array}$ & 0.50 & $\begin{array}{c}1 \\
1.00(0.71-1.44)\end{array}$ & 0.97 \\
\hline \multicolumn{5}{|c|}{ FIGO stage at primary surgery } \\
\hline $\begin{array}{l}1 \text { or } 2^{b} \\
3 \text { or } 4\end{array}$ & $2.90(1.98-4.24)$ & $<0.001$ & $\begin{array}{c}\mid \\
3.26(2.02-5.27)\end{array}$ & $<0.00$ \\
\hline
\end{tabular}

Abbreviations: FIGO = Federation of Gynaecology and Obstetrics; $\mathrm{HR}=$ hazard ratio $\mathrm{OS}=$ overall survival; $\mathrm{PFS}=$ progression-free survival; $95 \% \mathrm{Cl}=$ confidence interval

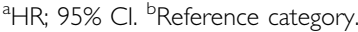

women with no residual disease and $50-70 \%$ in women with bulky residual tumours (Roberts et al, 1982; Barnhill et al, 1984; Podratz et al, 1985; Cain et al, 1986; Ayhan et al, 1991).

The literature regarding second-look surgery is rife with conflicting data. Although some authors reported a survival advantage for women undergoing second-look surgery who were completed and/or optimally debulked as compared with women not optimally debulked, others authors did not confirm these results. Second-look surgery was performed particularly during the 1980s and 1990s but over the last 10 years it has been abandoned from the vast majority of the gynaecological oncology centres as clinicians progressively recognised that up to $50 \%$ of women with proved pathological complete response to chemotherapy still face recurrent disease, with a median time to recurrence ranging between 14 and 24 months (Gershenson et al, 1985; Copeland et al, 1985; Rubin et al, 1991; Podratz and Cliby, 1994; NIH consensus conference, 1995). Nicoletto et al (1997) showed by a small RCT that although the second-look surgery in advanced stage ovarian cancer accurately defined the complete responders it failed to demonstrated a survival benefit.

When we launched this RCT, the second-look surgery was widely performed in Italian gynaecological cancer centres and we decided to investigate by a RCT if lymphadenectomy would improve survival in women with apparent complete clinical response to primary surgery and front-line chemotherapy who underwent second-look surgery and to verify the possible different peritoneal $v s$ nodal response to the chemotherapy.

Lymphadenectomy at the second look is aimed at removing small nodal metastases not otherwise detectable by clinical evaluation or palpation or by preoperative imaging. The potential benefit of this is the removal of resistant clones of tumour cells or of a poorly vascularised tumour (pharmacologic sanctuaries), which in turn, should decrease the likelihood of the early onset of drug resistance (Di Re et al, 1989; Burghardt and Winter, 1989; Scarabelli et al, 1995; Di Re et al, 1996). Apart from the potential survival advantage, the resection of lymph nodes at second-look surgery can avoid isolated lymph node recurrences that lead to a subsequent cytotoxic treatment or further nodal cytoreductive surgery followed by chemotherapy thus increasing morbidity and costs.

Only scanty data are available on the value of lymphadenectomy at second-look surgery (Wu et al, 1986; Burghardt et al, 1986). Baiocchi et al (1998) published a small cohort of 58 women, stage I-IV, with apparent complete response to chemotherapy, undergoing systematic lymphadenectomy between 1974 and 1993. In total, 15 out of 58 women $(26 \%)$ had nodal metastases. In particular, nodal metastases were found in $22 \%$ and $33 \%$ of women with early and advanced stage disease, respectively, and in $17.7 \%$ of women with no evidence of intraperitoneal disease compared with $64 \%$ of women with peritoneal residual disease at the second look. The only factors influencing the risk of relapse were the advanced stage, the grade 3 and the presence of residual disease at the primary surgery while no relation emerged between the relapse and the nodal status at the second look (relapse rate $27 \%$ vs $25 \%$ ). The rate of nodal metastases $(17.7 \%$ ) at the second look in this retrospective study is consistent with the data from Podratz et al (1988) who reported an exclusively nodal relapse in $20 \%$ of women with a pathological proved complete response.

The role of systematic lymphadenectomy, in the treatment of ovarian cancer, has been evaluated in three RCTs over 10 years. Systematic pelvic and aortic lymphadenectomy improved only staging in women with cancer confined to the pelvis and PFS in the advanced stage ovarian cancer, but it failed to demonstrate a survival benefit in either group (Benedetti-Panici et al, 2005; Maggioni et al, 2006).

The current RCT found that the systematic lymphadenectomy, compared with simple nodal biopsy, enabled to detect a higher number of patients with metastatic lymph nodes $(24.2 \%$ vs $13.3 \%)$. This study also showed that systematic lymphadenectomy is a relatively safe surgical procedure, if provided by trained gynaecology oncologists. Notwithstanding, systematic lymphadenectomy is associated with an increased operating time, blood loss, blood transfusions, hospital stay and a higher incidence of postoperative complications, consisting mainly of lymphocysts or lymphedema. Such data are in keeping with the results of the other two randomised studies in early or advanced ovarian cancer.

This trial was designed to assess OS as primary endpoint and PFS as secondary endpoint. We found that patients who underwent systemic lymphadenectomy had neither OS nor disease-free survival benefits when compared with patients who underwent removal of bulky nodes only. Furthermore, no difference in the pattern of relapse was found and also the number of nodal relapses was the same between the two groups (Table 5).

The stage of the disease at the moment of the diagnosis had a strong influence on the prevalence of nodal involvement at second look. When looking at patients enroled in the lymphadenectomy arm, only $10 \%$ of women staged IA-IIA had nodal metastases ( $4.5 \%$ in the 22 patients who underwent adjuvant chemotherapy) but this proportion increased to $27.2 \%$ in patients with more advanced disease at first diagnosis. These findings show that chemotherapy, although active, is not able to eradicate all cancer foci in lymph nodes, especially in advanced disease. Otherwise, markers of disease aggressiveness, namely residual tumour at the end of primary surgery and the presence of peritoneal macroscopic tumour at second-look surgery were strong predictor of nodal involvement. In fact, in the lymphadenectomy arm, the prevalence of nodal metastases was statistically correlated with the residual tumour at the primary surgery $(13.6 \%$ in patients with no residual tumour $v s 30.3 \%$ in patients with residual tumour, $P=0.165$ ), as well as with an evidence of peritoneal spread at the time of second look $(21.1 \%$ absent $v s 35.3 \%$ present, $P=0.088)$. Notably, both arms showed similar proportion of patients undergoing secondline chemotherapy, notwistanding wide difference in nodal involvement detection, and this allowed to explore the pure surgical debulking impact of lymphadenectomy on survival.

The limitations of our study must be ackwoledged. First, the trial took a long time to recruit and mature. Although many technological and scientific changes have occurred over such a long time the platinum-based chemotherapy regimens were widely used in this selected population and, above all, the randomisation procedure should have avoided the introduction of any systematic bias between arms. Another potential study limitation relates to the fact that second-look surgery, as performed in this trial, often tried to compensate first surgery inadequacy as shown in Table 2 where types of second look surgical procedures were described. The inappropriateness of first surgery, according to modern 
standards, was due to the fact that most of the patients were randomised in specialised clinics where patients were addressed after just diagnostic explorative surgery undergone in minor general hospitals.

Overall, our data showed a lack of benefit in overall and PFS in patients who underwent lymphadenectomy at second look. Subgroup analyses in early and advanced disease failed to show survival benefit as well. These results should discourage the use of routine lymphadenectomy at second-look surgery after firstline chemotherapy in women with ovarian cancer. Furthermore, among the 238 women with advanced stage disease, of which 220 women with no residual tumour at the end of second-look surgery (absent or surgical converted to absent), lymphadenectomy was not associated with a survival gain (HR for relapse: 1.06; 95\% $\mathrm{CI}=0.77-1.45 ; P=0.73$ and $\mathrm{HR}$ for death: $0.96 ; 95 \% \mathrm{CI}=$ $0.66-1.40 ; P=0.83)$. Currently, the lymphadenectomy in ovarian neoplasm international RCT, sponsored by the onco-gynaecologic

\section{REFERENCES}

Ayhan A, Yarali H, Develioğlu O, Uren A, Ozyilmaz F (1991) Prognosticators of second-look laparotomy findings in patients with epithelial ovarian cancer. J Surg Oncol 46: 222-225

Baiocchi G, Grosso G, Di Re E, Fontanelli R, Raspagliesi F, Di Re F (1998) Systematic pelvic and paraaortic lymphadenectomy at second look laparotomy for ovarian cancer. Gynecol Oncol 69: 151-156

Barnhill DR, Hoskins WJ, Heller PB, Park RC (1984) The second-look surgical reassessment for epithelial ovarian carcinoma. Gynecol Oncol 19: 148-154

Benedetti-Panici P, Greggi S, Maneschi F, Scambia G, Amoroso M, Rabitti C, Mancuso S (1993) Anatomical and pathological study of retroperitoneal nodes in epithelial ovarian cancer. Gynecol Oncol 51: 150-154

Benedetti-Panici P, Maggioni A, Hacker N, Landoni F, Ackermann S, Campagnutta E, Tamussino K, Winter R, Pellegrino A, Greggi S, Angioli R, Manci N, Scambia G, Dell'Anna T, Fossati R, Floriani I, Rossi RS, Grassi R, Favalli G, Raspagliesi F, Giannarelli D, Martella L, Mangioni C (2005) Systematic aortic and pelvic lymphadenectomy versus resection of bulky nodes only in optimally debulked advanced ovarian cancer: a randomized clinical trial. J Natl Cancer Inst 97: 560-566

Bristow RE, Tomacruz RS, Armstrong DK, Trimble EL, Monz FJ (2002) Survival effect of maximal cytoreductive surgery for advanced ovarian carcinoma during platinum era: a meta-analysis. J Clin Oncol 20: 1248-1259

Burghardt E, Winter R (1989) The effect of chemotherapy on lymph node metastases in ovarian cancer. Baillieres Clin Obstet Gynaecol 3: $167-171$

Burghadt E, Girardi F, Lahousen M, Tamussino K (1991) Patterns of pelvic and paraaortic lymph node involvement in ovarian cancer. Gynecol Oncol 40: 103-106

Burghardt E, Pickel H, Lahousen M, Stettner H (1986) Pelvic lymphadenectomy in operative treatment of ovarian cancer. Am J Obstet Gynecol 155: 315-319

Cain JM, Saigo PE, Pierce VK, Clark DG, Jones WB, Smith DH, Hakes TB, Ochoa M, Lewis Jr JL (1986) A review of second-look laparotomy for ovarian cancer. Gynecol Oncol 23: 14-25

Chen SS, Lee L (1983) Incidence of para-aortic and pelvic lymph-node metastases in epithelial carcinoma of the ovary. Gynecol Onco 116: 95-100

Copeland LJ, Gershenson DM, Wharton JT, Atkinson EN, Sneige N, Edwards CL, Rutledge FN (1985) Microscopic disease at second-look laparotomy in advanced ovarian cancer. Cancer 55: 472-478

Di Re F, Fontanelli R, Raspagliesi F, Di Re E (1989) Pelvic and paraaortic ymphadenectomy in cancer of the ovary. Bailliere's Clin Obstet Gynaecol 13: $131-142$

Di Re F, Baiocchi G, Fontanelli R, Grosso G, Cobellis L, Raspagliesi F, Di Re E. (1996) Systematic pelvic and paraaortic lymphadenectomy for advanced ovarian cancer: prognostic significance of node metastases. Gynecol Oncol 62: 360-365

FIGO Committee on Gynecologic Oncology (2009) FIGO staging classifications and clinical practice guidelines in the management of gynaecologic cancers. Int J Gynaecol Obstet 70: 209-262

Gershenson DM, Copeland LJ, Wharton JT, Atkinson EN, Sneige N, Edwards CL, Rutledge FN (1985) Prognosis of surgically determined complete responders in advanced ovarian cancer. Cancer 55: 1129-1135
German group AGO, that investigates the role of systematic lymphadenectomy at primary surgery in advanced stage IIB-IV ovarian cancer, completed debulked, has enroled almost 650 women and the results are awaited.

In conclusion, according to this RCT a systematic lymphadenectomy at the second-look surgery after first-line chemotherapy in women with ovarian cancer offers no benefit. When a secondlook surgery is required, because of an incomplete/inadequate endoperitoneal cytoreductive primary surgery, only nodal biopsies or removal of suspicious nodes should be performed, both in early and in advanced stage.

\section{ACKNOWLEDGEMENTS}

We thank Fondazione Mattioli, who provided support for Data Management.

Holschneider CH, Berek JS (2000) Ovarian cancer: epidemiology, biology, and prognostic factors. Semin Surg Oncol 19: 3-10

Kaplan EL, Meier P (1958) Nonparametric estimation from incomplete observations. J Am Stat Assoc 53: 457-481

Kigawa J, Minagawa Y, Itamochi H, Kanamori Y, Ishihara H, Terakawa N (1994) Retroperitoneal lymphadenectomy including the para-aortic nodes in patients with stage III ovarian cancer. Am J Obstet Gynecol 17: 230-233

Kikkawa F, Ishikawa H, Tamakoshi K, Suganuma N, Mizuno K, Kawai M, Arii Y, Tamakoshi A, Kuzuya K, Tomoda Y (1995) Prognostic evaluation of lymphadenectomy for epithelial ovariancancer. J Surg Oncol 60: 227-231

Maggioni A, Benedetti Panici P, Dell'Anna T, Landoni F, Lissoni A, Pellegrino A, Rossi RS, Chiari S, Campagnutta E, Greggi S, Angioli R, Manci N, Calcagno M, Scambia G, Fossati R, Floriani I, Torri V, Grassi R, Mangioni C (2006) Randomised study of systematic lymphadenectomy in patients with epithelial ovarian cancer macroscopically confined to the pelvis. Br J Cancer 95: 699-704

Nicoletto MO, Tumolo S, Talamini R, Salvagno L, Franceschi S, Visonà E, Marin G, Angelini F, Brigato G, Scarabelli C, Carbone A, Cecchetto A, Prosperi A, Rosabian A, Giusto M, Cima GP, Morassut S, Nascimben O, Vinante O, Fiorentino MV (1997) Surgical second look in ovarian cancer: a randomized study in patients with laparoscopic complete remission-a Northeastern Oncology Cooperative Group-Ovarian Cancer Cooperative Group Study. J Clin Oncol 15: 994-999

NIH consensus conference (1995) Ovarian cancer. Screening, treatment, and follow-up. NIH Consensus Development Panel on Ovarian Cancer. JAMA 273: 491-497

Parmar MKB, Machin D (1995) Survival analysis: a practical approach. John Wiley: Chichester (England)

Peto R, Pike MC, Armitage P, Breslow NE, Cox DR, Howard SV, Mantel N, McPherson K, Peto J, Smith PG (1977) Design and analysis of randomized clinical trials requiring prolonged observation of each patient. II. Analysis and examples. Br J Cancer 35: 1-39

Podratz KC, Malkasian Jr GD, Hilton JF, Harris EA, Gaffey TA (1985) Second-look laparotomy in ovarian cancer: evaluation of pathologic variables. Am J Obstet Gynecol 152: 230-238

Podratz KC, Cliby WA (1994) Second-look surgery in the management of epithelial ovarian carcinoma. Gynecol Oncol 55: S128-S133

Podratz KC, Malkasian Jr GD, Wieand HS, Cha SS, Lee RA, Stanhope CR, Williams TJ (1988) Recurrent disease after negative second-look laparotomy in stages III and IV ovarian carcinoma. Gynecol Oncol 29: 274-282

Roberts WS, Hodel K, Rich WM, DiSaia PJ (1982) Second-look laparotomy in the management of gynecologic malignancy. Gynecol Oncol 13: 345-355

Rubin SC, Hoskins WJ, Saigo PE, Chapman D, Hakes TB, Markman M, Reichman B, Almadrones L, Lewis Jr JL (1991) Prognostic factors for recurrence following negative second-look laparotomy in ovarian cancer patients treated with platinum-based chemotherapy. Gynecol Oncol 42: 137-141 
Scarabelli C, Gallo A, Zarrelli A, Visentin C, Campagnutta E (1995) Systematic pelvic and para-aortic lymphadenectomy during cytoreductive surgery in advanced ovarian cancer: potential benefit on survival. Gynecol Oncol 56: 328-337

Spirtos NM, Gross GM, Freddo JL, Ballon SC (1995) Cytoreductive surgery in advanced epithelial cancer of the ovary: the impact of aortic and pelvic lymphadenectomy. Gynecol Oncol 56: 345-352

Siegel R, Naishadham D, Jemal A. (20192) Cancer statistics (2012) CA Cancer J Clin 62: 10-29
Timmers PJ, Zwinderman K, Coens C, Vergote I, Trimbos JB (2010) Lymph node sampling and taking of blind biopsies are important elements of the surgical staging of early ovarian cancer. Int J Gynecol Cancer 20: 1142-1147 Trimbos B, Timmers P, Pecorelli S, Coens C, Ven K, van der Burg M, Casado A (2010) Surgical staging and treatment of early ovarian cancer: long-term analysis from a randomized trial. J Natl Cancer Inst 102: 982-987

Wu PC, Qu JY, Lang JH, Huang RL, Tang MY, Lian LJ (1986) Lymph node metastasis of ovarian cancer: a preliminary survey of 74 cases of lymphadenectomy. Am J Obstet Gynecol 155: 1103-1108

This work is published under the standard license to publish agreement. After 12 months the work will become freely available and the license terms will switch to a Creative Commons Attribution-NonCommercial-Share Alike 3.0 Unported License. 